\title{
Perencanaan Lift Hotel Bertingkat Tiga Puluh Berdasarkan SNI Nomor: 03-6573-2001
}

\author{
Ahmad Zayadi, Cahyono HP, Masyhudi \\ Program Studi Teknik Mesin Fakultas Teknik dan Sains Universitas Nasional, Jakarta \\ Korespondensi: tmesin_unas@yahoo.co.id
}

\begin{abstract}
ABSTRAK. Banyaknya gedung-gedung tinggi yang dibangun seperti zaman sekarang ini, menyebabkan tranportasi vertikal di antara lantai gedung-gedung tersebut semakin di butuhkan. Elevator atau lift merupakan salah satu dari alat transportasi vertikal yang banyak di gunakan saat ini, hal ini di sebabkan perjalanan antar lantai dengan menggunakan elevator di dalam gedung tersebut lebih menghemat waktu dan tenaga di bandingkan dengan menggunakan tangga. lift ini juga di bedakan jenisnya berdasarkan pemakaian, antara lain, lift untuk penumpang, lift untuk barang, lift untuk kendaraan, lift untuk pasien, dan juga lift dump waiters. Perencanaan bangunan ini adalah bangunan hotel berlantai tiga puluh dengan luasan perlantai $1200 \mathrm{~m}^{2}$. Pemasangan lift ini dibagi menjadi dua zona, zona 1 yaitu dari lantai 1sampai dengan lantai 15, dan zone 2 yaitu dari lantai 16 sampai dengan lantai 30 . Mempunyai waktu perjalanan bolak-balik untuk zona satu selama 159,2 detik, dan zona dua selama 167,04 detik. Membutuhkan 10 buah lift, mempunyai waktu menunggu untuk zona 1 selama 31,8 detik, dan untuk zona dua selama 33,4 detik. Mempunyai daya angkut untuk zona satu sebanyak 188 orang dan zona dua sebanyak 180 orang, beban puncak zona satu sebanyak 138 orang dan 158 orang, daya listrik untuk zona satu sebesar $204 \mathrm{Kwh}$ dan zona dua sebesar $340 \mathrm{Kwh}$.
\end{abstract}

Kata Kunci : Perencanaan, Elevator, SNI

\begin{abstract}
The many tall buildings are built like nowadays, causing vertical transportation between floors of buildings are increasingly in need. Elevator or lift is one of the means of transportation verticals much in use today, this is caused travel between floors with an elevator in the building save time and effort in comparison with using a ladder. This lift is also differentiated by the type of use, among other things, an elevator for passengers, elevators for goods, lifts for vehicles, elevators for patients, and lift dump waiters. Planning of this building is a thirty-story hotel building with an area of $1200 \mathrm{~m}^{2}$ perlantai. Installation of the lift is divided into two zones, zone 1 is from the 1st floor up to the 15th floor, and zone 2 is from the 16th floor to the 30th floor Carries time traveling back and forth to one zone for 159.2 seconds, and two zones for 167.04 seconds. Requires 10 pieces of the lift, have time to wait for zone 1 for 31.8 seconds, and for the two zones for 33.4 seconds. Has a carrying capacity for as many as 188 people of the zone and two zones of 180 people, the peak load of the zone by 138 people and 158 people, power to the zone of 204 Kwhdan two zones of $340 \mathrm{Kwh}$.
\end{abstract}

Keywords: Planning, Elevator, SNI.

\section{PENDAHULUAN}

Lift adalah angkutan transportasi vertikal yang digunakan untuk mengangkut orang atau barang. Lift umumnya digunakan di gedung-gedung bertingkat tinggi; biasanya lebih dari tiga atau empat lantai. Gedung-gedung yang lebih rendah biasanya hanya mempunyai tangga atau eskalator. Liftlift pada zaman modern mempunyai tombol-tombol yang dapat dipilih penumpangnya sesuai lantai tujuan mereka, Terdapat tiga jenis mesin, yaitu Hidraulik, Traxon atau katrol tetap, dan Hoist atau katrol ganda, Jenis hoist dapat dibagi lagi menjadi dua bagian, yaitu hoist dorong dan hoist tarik.

Lift ini, sering disebut elevator, yang merupakan alat angkut untuk mengangkut orang atau barang dalam suatu bangunan yang tinggi. Lift dapat dipasang untuk bangunan yang tingginya lebih dari 4 lantai, karena kemampuan orang untuk naik turun dalam menjalankan tugasnya hanya mampu dilakukan sampai 4 lantai. 
Aspek yang harus ditinjau dalam perencanaan lift adalah lokasi dan konfigurasi layout, jumlah, kapasitas dan kecepatan, grouping, single deck atau double deck, sky lobby dengan shuttle service, zoning (high rise atau express lift dan low rise).

Beberapa faktor yang mempengaruhi pertimbangan pemilihan system desain lift adalah jumlah lantai yang dilayani, Jarak lantai ke lantai, Jumlah penghuni tiap-tiap lantai, Lokasi gedung, Penggunaan khusus lift dalam gedung, Lantai-lantai khusus, Fungsi gedung. Pemilihan lift didasarkan atas persyaratan dasar sebagai berikut: (a) Kecepatan dan kapasitas harus sesuai dengan tinggi dan luas bangunan, (b) Konfigurasi susunan dan tata letak lift, (c) Pemilihan jenis motor penggerak dan jenis kendali operasi

Pada bangunan yang tinggi dan luas, jumlah lif yang diperlukan meningkat sebanding dengan jumlah lantai yang dilayani. Dengan demikian, jika mencapai suatu ketinggian tertentu, maka areal luas yang digunakan untuk menempatkan lif menjadi meningkat dan melebihi ketentuan ekonomis (di atas 20\% luas lantai). Jadi, pada umumnya sebuah lif hanya melayani sekitar 12 15 lantai, agar tidak melampaui batas tunggu dan jumlah waktu perjalanan yang disyaratkan.

Pengaturan tata lift pada lobby yang dikaitkan dengan pembagian zona layanan lift dapat dilihat pada berikut ini. Tiap zona lif biasanya melayani 10 - 15 lantai, dan 4 zona merupakan batas maksimum. Jika memerlukan zona lift lebih dari empat, maka harus menggunakan sky lobby (minimum dua lantai). Dan di atas sky lobby masih dimungkinkan untuk ditambah $2-3$ lantai tambahan untuk ruang mekanikal/elektrikal.

\section{METODOLOGI PENELITIAN}

Dalam sistem pengoprasiannya, di gunakan rangkaian elektrik yang dirangkai dalam satu panel kontrol. Rangkaian tersebut terdiri dari relay, contactor, limit switch, dan lain-lain. Sangkar dapat dipanggil dan berhenti di masing-masing lantai, tergantung perintah dengan cara menekan tomboloperasional. Perencanaan Lift dapat dibuat diagram alir seperti gambar 1.

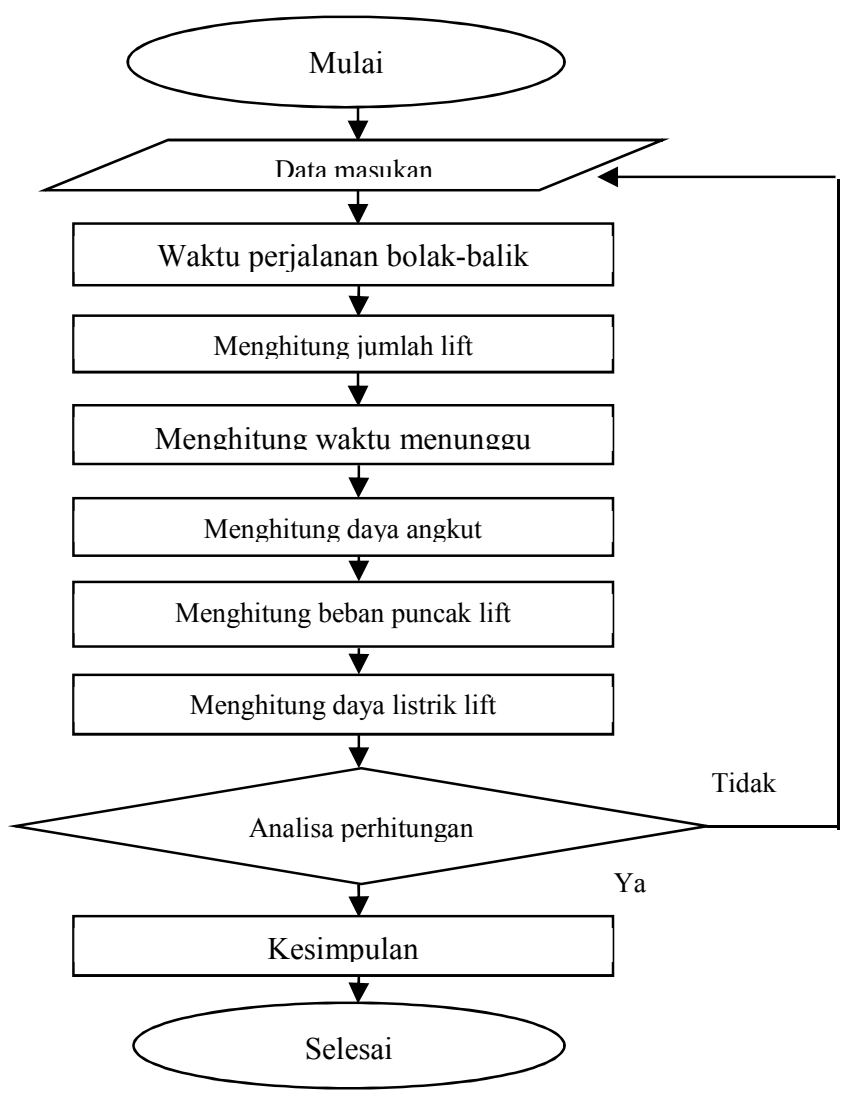

GAMBAR 1. Diagram Alir Perencanaan Lift 
Lift ini direncanakan dapat mengangkut muatan sebesar $\mathrm{M}=1350 \mathrm{~kg}$. Lift ini di harapkan dapat beroperasi mengantar penumpang dari lantai kelantai lainnya yang menghubungkan lantai satu ke lantai lainnya, sesuai perintah pengoprasiannya.

Adapun data masukan dalam perancangan Lift passanger adalah :
Luas Bangunan
: $1200 \mathrm{~m}^{2}$
Tinggi Bangunan $\quad: 126 \mathrm{~m}$
Tinggi Perlantai $\quad: 4,20 \mathrm{~m}$
Jumlah lantai $\quad: 30$ lantai
Luas perkamar $\quad: 25 \mathrm{~m}^{2}$
Jumlah kamar 1 lantai : 31 kamar
Jumlah seluruh kamar : 868 kamar
Lift di bagi 2 zona : Zona 1, lantai 1-15
Zona 2, lantai $15-30$

Keceptan rata-rata motor: Zona $1=3 \mathrm{~m} / \mathrm{s}$

: Zona $2=5 \mathrm{~m} / \mathrm{s}$

TABEL 1. Data Hotel.

\begin{tabular}{|c|c|c|c|c|c|}
\hline No & Lantai & Fungsi & Bad room & Populasi (orang) & $\operatorname{Luas}\left(\mathbf{m}^{2}\right)$ \\
\hline 1 & Lantai - 1 & Loby 1 & - & - & 1200 \\
\hline 2 & Lantai - 2 & Kamar hotel & 31 & 62 & 1200 \\
\hline 3 & 3 & Kamar hotel & 31 & 62 & 1200 \\
\hline 4 & 4 & Kamar hotel & 31 & 62 & 1200 \\
\hline 5 & 5 & Kamar hotel & 31 & 62 & 1200 \\
\hline 6 & 6 & Kamar hotel & 31 & 62 & 1200 \\
\hline 7 & 7 & Kamar hotel & 31 & 62 & 1200 \\
\hline 8 & 8 & Kamar hotel & 31 & 62 & 1200 \\
\hline 9 & 9 & Kamar hotel & 31 & 62 & 1200 \\
\hline 10 & 10 & Kamar hotel & 31 & 62 & 1200 \\
\hline 11 & 11 & Kamar hotel & 31 & 62 & 1200 \\
\hline 12 & 12 & Kamar hotel & 31 & 62 & 1200 \\
\hline 13 & 13 & Kamar hotel & 31 & 62 & 1200 \\
\hline 14 & 14 & Kamar hotel & 31 & 62 & 1200 \\
\hline 15 & Lantai - 15 & Kamar hotel & 31 & 62 & 1200 \\
\hline 16 & Lantai - 16 & Loby 2 & - & - & 1200 \\
\hline 17 & 17 & Kamar hotel & 31 & 62 & 1200 \\
\hline 18 & 18 & Kamar hotel & 31 & 62 & 1200 \\
\hline 19 & 19 & Kamar hotel & 31 & 62 & 1200 \\
\hline 20 & 20 & Kamar hotel & 31 & 62 & 1200 \\
\hline 21 & 21 & Kamar hotel & 31 & 62 & 1200 \\
\hline 22 & 22 & Kamar hotel & 31 & 62 & 1200 \\
\hline 23 & 23 & Kamar hotel & 31 & 62 & 1200 \\
\hline 24 & Lantai - 24 & Kamar hotel & 31 & 62 & 1200 \\
\hline 25 & Lantai - 25 & Kamar hotel & 31 & 62 & 1200 \\
\hline 26 & 26 & Kamar hotel & 31 & 62 & 1200 \\
\hline 27 & 27 & Kamar hotel & 31 & 62 & 1200 \\
\hline 28 & 28 & Kamar hotel & 31 & 62 & 1200 \\
\hline 29 & 29 & Kamar hotel & 31 & 62 & 1200 \\
\hline 30 & Lantai - 30 & Kamar hotel & 31 & 62 & 1200 \\
\hline 31 & Lantai atap & - & - & - & 1200 \\
\hline 32 & Jumlah & - & 868 & 1736 & \\
\hline
\end{tabular}

\section{MENGHITUNG KEBUTUHAN LIFT PENUMPANG}

\section{Menghitung Perjalanan Bolak-Balik (T)}

Perjalanan bolak-balik lift $(\mathrm{T})$

$$
\mathrm{T}=\frac{(2 h+4 s)(n-1)+s(3 m+4)}{s}
$$


Karena gedung ini di bagi dalam 2 zone, maka waktu perjalanan perjalanan bolak-balik dibagi menjadi 2 zone, maka, perhitungan waktu perjalanan bolak balik untuk zone 2 menjadi:

$$
\begin{aligned}
& \mathrm{T}_{2}=\frac{2 \mathrm{~h}(\mathrm{n}-1)}{\mathrm{s}_{2}}+\frac{\left(2 \mathrm{~h}+4_{2}\right)\left(\mathrm{n}_{2}-1\right)+\mathrm{s}_{2}(3 \mathrm{~m}+4)}{\mathrm{s}_{2}} \\
& \mathrm{~T}_{2}=\frac{2 \mathrm{~h}\left(\mathrm{n}_{1}-1\right)+\left(2 \mathrm{~h}+4 \mathrm{~s}_{2}\right)\left(\mathrm{n}_{2}-1\right)+\mathrm{s}_{2}(3 \mathrm{~m}+4)}{\mathrm{s}_{2}} \\
& \mathrm{~T}_{2}=\frac{2 \times 4,20(15-1)+(2 \times 4,20+4 \times 5)(15-1)+5(3 \times 20+4)}{5} \\
& \mathrm{~T}_{2}=\frac{8,4 \times(14)+28,4 \times(14)+5 \times(64)}{5} \\
& \mathrm{~T}_{2}=\frac{117,6+397,6+320}{5} \\
& \mathrm{~T}_{2}=\frac{835,2}{5} \\
& \mathrm{~T}_{2}=167,04 \text { detik }
\end{aligned}
$$

Untuk perhitungan waktu perjalanan bolak balik untuk zone 1:

$$
\begin{aligned}
& \mathrm{T}_{1}=\frac{\left(2 \mathrm{~h}+4 \mathrm{~s}_{1}\right)\left(\mathrm{n}_{1}-1\right)+\mathrm{s}_{1}(3 \mathrm{~m}+4)}{\mathrm{s}_{1}} \\
& \mathrm{~T}_{1}=\frac{(2 \times 4,20+4 \times 3) \times(15-1)+3(3 \times 20+4)}{3} \\
& \mathrm{~T}_{1}=\frac{(8,4+12) \times(14)+3(60+4)}{3} \\
& \mathrm{~T}_{1}=\frac{285,6+192}{3} \\
& \mathrm{~T}_{1}=159,2 \text { detik }
\end{aligned}
$$

\section{Menghitung Jumlah Lift Untuk Kebutuhan Gedung}

Untuk

$$
\begin{aligned}
& \mathrm{a}=1200 \mathrm{~m}^{2} \\
& \mathrm{n}_{2}=15 \\
& \mathrm{~T}_{2}=167,04 \text { detik } \\
& \mathrm{P}=5 \% \\
& \mathrm{a}^{\prime \prime}=5 \mathrm{~m}^{2} / \text { orang } \\
& \mathrm{m}=20 \text { orang/lift }
\end{aligned}
$$

- Untuk menentukan jumlah lift dalam zone 2:

Beban puncak lift zone 2:

$$
\mathrm{L}_{2}=\frac{\mathrm{P}\left(2 \mathrm{a}-3 \mathrm{mN}_{2}\right) \mathrm{n}_{2}}{2 \mathrm{a}}
$$

Daya angkut lift 5 menit untuk zone 2 :

$$
\begin{aligned}
& \text { persamaan } \mathrm{L}_{2}=\mathrm{M}_{2} \\
& \frac{\mathrm{n}^{2} \mathrm{p}\left(2 \mathrm{a}-3 \mathrm{mN}^{2}\right)}{2 \mathrm{a}^{\prime \prime}}=\frac{300 \mathrm{mN}_{2}}{\mathrm{~T}_{2}}
\end{aligned}
$$

Maka $\mathrm{N}_{2}=\frac{2 \mathrm{an}_{2} \mathrm{~T}_{2} \mathrm{p}}{600 \mathrm{a} m+\mathrm{mn}_{2} \mathrm{~T}_{2} \mathrm{p}}$

$$
\begin{aligned}
& \mathrm{N}_{2}=\frac{2 \times 1200 \times 15 \times 167,04 \times 5 \%}{600 \times 5 \times 20+20 \times 15 \times 167.04 \times 5 \%} \\
& \mathrm{~N}_{2}=5 \text { lift }
\end{aligned}
$$

- Menentukan jumlah lift dalam zone 1:

Beban puncak lift zone 1: 


$$
\mathrm{L}_{1}=\frac{\mathrm{P}\left(2 \mathrm{a}-3 \mathrm{~m}\left(\mathrm{~N}_{1}+\mathrm{N}_{2}\right)\right) \mathrm{n}_{1}}{2 \mathrm{a} "}
$$

Daya angkut lift 5 menit untuk zone 1 :

$$
\begin{gathered}
\mathrm{M}_{1}=\frac{300 \times \mathrm{m} \mathrm{x} \mathrm{N}}{\mathrm{T}_{1}} \\
\text { persamaan } \mathrm{L}_{2}=\mathrm{M}_{2} \\
\frac{\mathrm{n}_{1} \mathrm{p}\left(2 \mathrm{a}-3 \mathrm{mN}_{1}\right)}{2 \mathrm{a} "}=\frac{300 \mathrm{mN}_{1}}{\mathrm{~T}_{1}} \\
\text { Maka } \mathrm{N}_{1}=\frac{2 \mathrm{n}_{1} \mathrm{~T}_{1} \mathrm{p}(\mathrm{a}-6 \mathrm{~m})}{600 \mathrm{a} " \mathrm{~m}+3 \mathrm{mn}_{1} \mathrm{~T}_{1} \mathrm{p}} \\
\mathrm{N}_{1}=\frac{2 \times 15 \times 159,2 \times 5 \%(1200-6 \times 20)}{600 \times 5 \times 20+3 \times 20 \times 15 \times 5 \%} \\
\mathrm{~N}_{1}=5 \mathrm{lift}
\end{gathered}
$$

\section{Waktu Menunggu (W)}

Menghitung waktu menunggu untuk zone 1:

$$
\begin{aligned}
& \mathrm{W}_{1}=\frac{\mathrm{T}_{1}}{\mathrm{~N}_{1}} \\
& \mathrm{~W}_{1}=\frac{159,2}{5} \\
& \mathrm{~W}_{1}=31,8 \text { detik }>\mathrm{Wmin}=30 \text { detik } \\
& \quad<\mathrm{Wmax}=60 \text { detik }
\end{aligned}
$$

Menghitung waktu tunggu untuk zone 2:

$$
\begin{array}{ll}
\mathrm{W}_{2}=\frac{\mathrm{T}_{2}}{\mathrm{~N}_{2}} & \\
\mathrm{~W}_{2}=\frac{167,04}{5} & \\
\mathrm{~W}_{2}=33,4 \text { detik } & >\mathrm{Wmin}=30 \text { detik } \\
& <\mathrm{Wmax}=60 \text { detik }
\end{array}
$$

\section{Daya Angkut Lift (M)}

Daya angkut (M) 1 lift dalam 5 menit:

$$
\mathrm{M}=\frac{5 \times 60 x m}{w}=\frac{300}{\mathrm{~T}}
$$

Daya angkut 4 lift dalam 5 menit:

$$
\mathrm{M}=\frac{300 \times \mathrm{m} \times \mathrm{N}}{\mathrm{T}}
$$

- Menghitung daya angkut lift pada zona 1:

$$
\begin{aligned}
& \mathrm{M}_{1}=\frac{300 \times \mathrm{m} \mathrm{N} \mathrm{N}_{1}}{\mathrm{~T}_{1}} \\
& \mathrm{M}_{1}=\frac{300 \times 20 \times 5}{159,2} \\
& \mathrm{M}_{1}=188 \text { Orang }
\end{aligned}
$$

- Menghitung daya angkut lift pada zona 2 :

$$
\begin{aligned}
& \mathrm{M}_{2}=\frac{300 \times \mathrm{m \times} \mathrm{N}}{\mathrm{T}_{2}} \\
& \mathrm{M}_{2}=\frac{300 \times 20 \times 5}{167,04} \\
& \mathrm{M}_{2}=180 \text { orang }
\end{aligned}
$$

\section{Beban Puncak Lift (L)}

Menghitung beban puncak lift adalah $L=\frac{P(a-k)}{a^{\prime \prime}}$

Dimana: $\quad \mathrm{L}=$ Beban puncak 


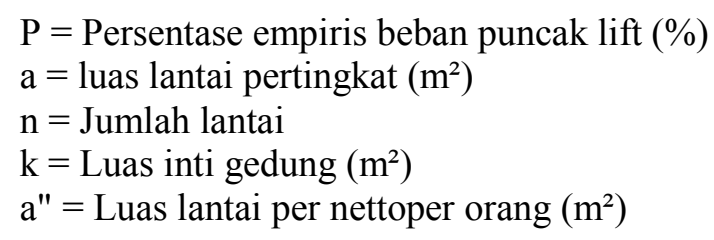

Sedangkan $\mathrm{M}=\frac{5 \times 60 \times \mathrm{m}}{\mathrm{w}}=\lambda$

Maka $L=\frac{P(a-1,5 m N) n}{a^{\prime \prime}}$

$\left[\mathrm{L}=\frac{\mathrm{P}(2 \mathrm{a}-3 \mathrm{mN}) \mathrm{n}}{2 \mathrm{a}}\right]$

- Menghitung beban puncak lift zone 1:

$$
\begin{aligned}
& \mathrm{L}_{1}=\frac{\mathrm{P}\left(2 \mathrm{a}-3 \mathrm{~m}\left(\mathrm{~N}_{1}+\mathrm{N}_{2}\right) \mathrm{n}_{1}\right.}{2 \mathrm{a}^{\prime}} \\
& \mathrm{L}_{1}=\frac{5 \%(2 \times 1200-3 \times 20 \times 10) \times 15}{2 \times 5} \\
& \mathrm{~L}_{1}=\frac{0,05(1800) \times 15}{10} \\
& \mathrm{~L}_{1}=134 \text { orang }
\end{aligned}
$$

- Menghitung beban puncak zonez 2 :

$$
\begin{aligned}
\mathrm{L}_{2} & =\frac{\mathrm{P}\left(2 \mathrm{a}-3 \mathrm{mN}_{2}\right) \mathrm{n}_{2}}{2 \mathrm{a} "} \\
\mathrm{~L}_{2} & =\frac{5 \%(2 \times 1200-3 \times 20 \times 5) \times 15}{2 \times 5} \\
\mathrm{~L}_{2} & =\frac{0,05(2100) \times 15}{10} \\
\mathrm{~L}_{2} & =158 \text { orang }
\end{aligned}
$$

\section{Daya Listrik Untuk Lift (E)}

Suatu lift dengan kapasitas $\mathrm{m}$ dan kecepatan $\mathrm{s} \mathrm{m} /$ detik memerlukan daya :

$$
\left[\mathrm{E}=\frac{0,75 \times \mathrm{m} \mathrm{x} \mathrm{s}}{75} \mathrm{HP}\right]=0,75 \mathrm{~ms} \mathrm{kw}
$$

Sedangkan faktor kebutuhan daya untuk suatu kelompok lift (tabel 2) adalah:

TABEL 2. Faktor Kebutuhan Daya Kelompok Lift

\begin{tabular}{|c|c|c|c|c|c|c|c|c|c|c|}
\hline Jumlah lift & 2 & 3 & 4 & 5 & 6 & 7 & 10 & 15 & 20 & 25 \\
\hline Faktor daya & 0,85 & 0,77 & 0,72 & 0.67 & 0,63 & 0,59 & 0,52 & 0,44 & 0,40 & 0,35 \\
\hline
\end{tabular}

- Perhitungan untuk zona 1:

$$
\mathrm{E}=\frac{0,75 \times 1350 \times 3}{75} \mathrm{HP}=41 \mathrm{HP}
$$

Untuk 5 lift $=0,67 \times 5 \times 41 \mathrm{HP}=137 \mathrm{HP}$

Penggunaan daya listrik oleh lift (10 jam/hari):

$\mathrm{Kwh}=0,20 \times 137 \times \frac{0,746}{\mathrm{HP}} \times 10 \mathrm{jam}=204 \mathrm{Kwh}$

- Perhitungan untuk zona 2 :

$\mathrm{E}=\frac{0,75 \times 1350 \times 5}{75} \mathrm{HP}=68 \mathrm{HP}$

Untuk 4 lift $=0,67 \times 5 \times 68=228 \mathrm{HP}$

$\mathrm{Kwh}=0,20 \times 228 \times \frac{0,746}{\mathrm{HP}} \times 10 \mathrm{jam}=340 \mathrm{Kwh}$ 


\section{HASIL DAN PEMBAHASAN}

Dalam merancang lift dalam sebuah gedung kita tidak bisa hanya asal menghitung kebutuhan lift yang akan di pergunakan, karena itu menyangkut dalam kenyamanan pengunjung saat ingin menggunakan lift. Lift ini di tetapkan dapat mengangkut sebesar $M=1350 \mathrm{~kg}$, Dari hasil perhitungan diperoleh beberapa hasil perhitungan, langkah awal dalam perhitungan perancangan lift adalah sebagai berikut:

- Luas bangunan adalah $(\mathrm{a})=1200 \mathrm{~m}^{2}$, dan tinggi perlantai $(\mathrm{h})=4.20 \mathrm{~m}^{2}$

- Waktu perjalanan bolak balik zone 2

$$
\left(\mathrm{T}_{2}\right)=\frac{2 \mathrm{~h}\left(\mathrm{n}_{1}-1\right)+\left(2 \mathrm{~h}+4 \mathrm{~s}_{2}\right)\left(\mathrm{n}_{2}-1\right)+\mathrm{s}_{2}(3 \mathrm{~m}+4)}{\mathrm{s}_{2}}=167,04 \text { detik }
$$

Waktu perjalanan bolak balik zone 1

$$
\mathrm{T}_{1}=\frac{\left(2 \mathrm{~h}+4 \mathrm{~s}_{1}\right)\left(\mathrm{n}_{1}-1\right)+\mathrm{s}_{1}(3 \mathrm{~m}+4)}{\mathrm{s}_{1}}=159,2 \text { detik }
$$

- Menentukan jumlah lift

a. Untuk zone 1 di tentukan lift berjumlah $(\mathrm{N})=5$ buah

b. Untuk zone 2 lift juga di tentukan berjumlah $(\mathrm{N})=5$ buah

- Waktu menunggu lift

a. Untuk zona 1 waktu menunggu selama $(\mathrm{W})=31,8$ detik

b. Untuk zona 2 waktu menunggu selama $(\mathrm{W})=33,4$ detik

- Untuk daya angkut lift dalam 5 menit sebanyak:

a. Untuk zona $1 \mathrm{M}_{1}=\frac{300 \times \mathrm{m} \mathrm{x} \mathrm{N}}{\mathrm{T}_{1}}=188$ Orang

b. Untuk zona $2 \mathrm{M}_{2}=\frac{300 \times \mathrm{m} \mathrm{x} \mathrm{N}}{\mathrm{T}_{2}}=180$ Orang

- Beban puncak lift

a. Untuk zona 1 beban puncak $\left(\mathrm{L}_{1}\right)=134$ Orang

b. Untuk zona 2 beban puncak $\left(\mathrm{L}_{2}\right)=158$ Orang

Maka beban puncak dari kedua zone aman untuk digunakan.

\section{KESIMPULAN}

Lift adalah angkutan transportasi vertikal yang digunakan untuk mengangkut orang atau barang. Lift umumnya digunakan di gedung-gedung bertingkat tinggi; biasanya lebih dari tiga atau empat lantai. Gedung-gedung yang lebih rendah biasanya hanya mempunyai tangga atau eskalator. Berdasarkan uraian di atas, maka dapat disimpulkan untuk pemasangan lift ini di bagi menjadi 2 zona, zona 1 yaitu dari lantai $1 \mathrm{~s} / \mathrm{d}$ lantai 15, dan zone 2 yaitu dari lantai 16s/d lantai 30. Untuk waktu perjalanan bolak-balik di dapat $\left(T_{1}\right)=159,2$ detik, dan $\left(T_{2}\right)=167,04$ detik. Hotel ini membutuhkan lift untuk zona $1\left(\mathrm{~N}_{1}\right)=5$ buah lift, dan zona $2\left(\mathrm{~N}_{2}\right)=5$ buah lift. Kesabaran orang untuk menunggu lift tergantung kota dan negara di mana gedung itu ada. Waktu menunggu $=$ waktu perjalanan bolak-balik dibagi jumlah lift $w=\frac{T}{N}$, dan $\left(\mathrm{W}_{1}\right)=31,8$ detik, dan $\left(\mathrm{W}_{2}\right)=33,4$ detik.

Daya angkut lift tergantung dari kapasitas dan frekuensi pemuatannya. Standard daya angkut lift diukur untuk jangka waktu 5 menit jam jam sibuk (rush-hour). dan untuk $\left(\mathrm{M}_{1}\right)=188$ Orang, dan $\left(\mathrm{M}_{2}\right)=180$ Orang. Beban puncak diperhitungkan berdasarkan, persentasi empiris terhadap 
jumlah penghuni gedung, yang diperhitungkan harus terangkat oleh lift-lift dalam 5 menit pertama jam-jam padat (rush-hour). Untuk $\left(\mathrm{L}_{1}\right)=134$ Orang, dan $\left(\mathrm{L}_{2}\right)=158$ Orang.

Kecepatan rata-rata motor untuk zone 1 adalah $3 \mathrm{~m} / \mathrm{s}$, dan untuk zone 2 adalah $5 \mathrm{~m} / \mathrm{s}$. Daya listrik yang diperlukan untuk $\left(E_{1}\right)=204 \mathrm{Kwh}$, dan $\left(E_{2}\right)=340 \mathrm{Kwh}$.

\section{DAFTAR PUSTAKA}

[1] Foead, Nazar. "Mesin Pesawat Angkat", Erlangga, Jakarta, 1996.

[2] Rudenco. N (terjemah : N. Foead) "Mesin Pengangkat", Erlangga, Jakarta, 1996

[3] SNI Nomor : 03-6573-2001

[4] Sunarno, "Mekanikal Elektrikal" Andi Offset, Yogyakarta, 2005.

[5] Strakoch, George. R dan Caporale, Robert. S "The Vertical Transportation hand book", Fourth Edition, Wiley, New Jersey, 2010. 